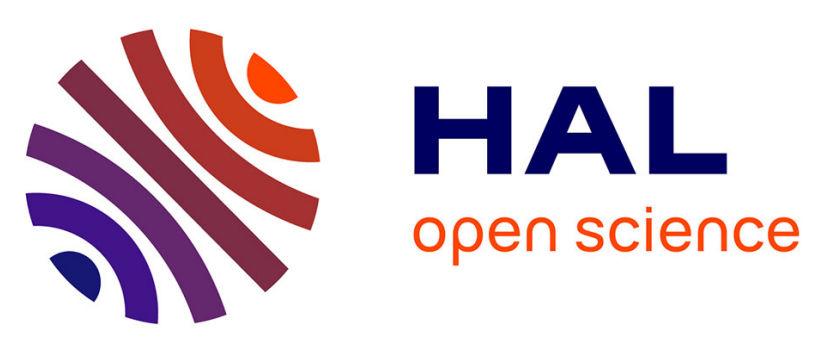

\title{
Existence and interpretation of too high excluded volume exponents in the apparent scaling laws for polymer dimensions in a poor solvent
}

J. François, T. Schwartz, G. Weill

\section{- To cite this version:}

J. François, T. Schwartz, G. Weill. Existence and interpretation of too high excluded volume exponents in the apparent scaling laws for polymer dimensions in a poor solvent. Journal de Physique Lettres, 1980, 41 (1), pp.9-11. 10.1051/jphyslet:019800041010900 . jpa-00231711

\section{HAL Id: jpa-00231711 \\ https://hal.science/jpa-00231711}

Submitted on 1 Jan 1980

HAL is a multi-disciplinary open access archive for the deposit and dissemination of scientific research documents, whether they are published or not. The documents may come from teaching and research institutions in France or abroad, or from public or private research centers.
L'archive ouverte pluridisciplinaire HAL, est destinée au dépôt et à la diffusion de documents scientifiques de niveau recherche, publiés ou non, émanant des établissements d'enseignement et de recherche français ou étrangers, des laboratoires publics ou privés. 


\title{
Existence and interpretation of too high excluded volume exponents in the apparent scaling laws for polymer dimensions in a poor solvent
}

\author{
J. François, T. Schwartz and G. Weill \\ Centre de Recherches sur les Macromolécules, CNRS, and Université Louis-Pasteur, Strasbourg, France
}

(Reçu le 20 septembre 1979, accepté le 13 novembre 1979)

\begin{abstract}
Résumé. - On montre que si la transition d'une statistique gaussienne à une statistique de volume exclu s'effectue de manière progressive à partir d'un nombre de chaînons $N_{\mathrm{c}}$, des grandeurs telles que le rayon de giration ou le facteur de diffusion peuvent présenter des exposants effectifs supérieurs à l'exposant asymptotique de volume exclu dans un domaine de $N$ compris entre 10 et $100 N_{\mathrm{c}}$. Ce modèle pourrait expliquer en particulier les résultats observés pour le système polyacrylamide-eau pour lequel $N_{\mathrm{c}}$ est grand à température ordinaire.
\end{abstract}

\begin{abstract}
It is shown that if the transition from a gaussian to an excluded volume statistics takes place progressively starting from a number of links $N_{\mathrm{c}}$, some quantities such as the radius of gyration or the scattering curve scale with effective exponents higher than the asymptotical excluded volume exponent for $10 N_{\mathrm{c}}<N<100 N_{\mathrm{c}}$. This model could in particular explain the results observed with the polyacrylamide-water system, where $N_{\mathrm{c}}$ is large at room temperature.
\end{abstract}

In the course of a systematic study of well fractionated samples of unhydrolized polyacrylamide in $0.1 \mathrm{M} \mathrm{NaCl}$ water solutions, an abnormally high exponent has been found in the radius of gyrationmolecular weight power law [1]

$$
R_{\mathrm{G}}=0.0749 \mathrm{M}^{0.64} \text {. }
$$

The departure of the exponent from its expected classical value $v=0.60$ has been confirmed by two other measurements.

First a careful examination of the asymptotical behaviour of the scattering curve $S(q)$ has been performed by light scattering on very high molecular weight samples [1]. The value of $v$ obtained from the $q^{1 / 2}$ linear behaviour at high $q$ is furthermore confirmed by the fact that the intercept of the asymptot with the $q=0$ axis depends upon the polydispersity index $M_{\mathrm{w}} / M_{\mathrm{n}}$ [2] and that it has been found fully consistent with the experimental value of this ratio as measured by gel permeation chromatography.

Secondly, translational diffusion $D$, sedimentation velocity $S$ and intrinsic viscosity $[\eta]$ measurements have been performed [3]. These dynamic quantities depend on both the static $R_{\mathrm{G}}$ and dynamic radius $R_{\mathrm{D}}$. The molecular weight dependence of $R_{\mathrm{G}}$ can be obtained, combining [ $\eta]$ and $S$ or $[\eta]$ and $D$ and $M[4]$

$$
R \alpha[\eta] S \alpha[\eta] M D \text {. }
$$

A plot of these quantities confirm the value $v=0.64$.

Measurements of the dimensions of the same polymer in a water-methanol $\theta$ mixture leads to the power law [5]

$$
\left(R_{\mathrm{G}}\right)_{\theta}=0.39 M^{0.50} .
$$

The molecular weight $M^{*}$ at which the two power laws (1) and (3) $\left(M^{*} \sim 130.000\right)$ cross, is related to the chemical distance $N_{\mathrm{c}}$ required for the development of excluded volume effects in the monomer-monomer pair correlation function. It is related to the reduced temperature

$$
\tau=\frac{T-\theta}{T} \text { by } N_{\mathrm{c}} \sim \tau^{-2}[6] .
$$

This high value of $M^{*}$ indicates a rather poor solvent at room temperature. Therefore for the whole range of molecular weights that we have studied $M / M^{*}$ remains small and one is led to think of possible effects of cross over on the effective index

$$
v_{\mathrm{G}}=\frac{\partial \operatorname{Ln} R_{\mathrm{G}}}{\partial \operatorname{Ln} N} .
$$

A calculation of $v_{\mathrm{G}}$ for small values of $N / N_{\mathrm{c}}$ has been performed by Weill and des Cloizeaux [7] under the simplest possible assumption for the cross over of the pair correlation function at $N_{\mathrm{c}}$. It 
corresponds to an abrupt change in the scaling law for the mean distance between monomer $i$ and $j$ :

$$
\begin{array}{ll}
\left\langle r_{i j}^{2}\right\rangle=|i-j| a^{2} ; & i-j<N_{\mathrm{c}} \\
\left\langle r_{i j}^{2}\right\rangle=N_{\mathrm{c}}\left(\frac{i-j}{N_{\mathrm{c}}}\right)^{2 v} a^{2} ; & i-j>N_{\mathrm{c}}
\end{array}
$$

$a$ being the statistical segment length.

Introduction in the double sum

$$
R_{\mathrm{G}}^{2}=\frac{1}{2 N^{2}} \sum_{i} \sum_{j}\left\langle r_{i j}^{2}\right\rangle
$$

and replacement by integrals with $p=i-j$ leads to

$$
\begin{aligned}
R_{\mathrm{G}}^{2} & =\frac{a^{2}}{N^{2}} \int_{0}^{N_{\mathrm{c}}} p(N-p) \mathrm{d} p-\int_{0}^{N_{\mathrm{c}}} N_{\mathrm{c}}\left(\frac{p}{N_{\mathrm{c}}}\right)^{2 v}(N-p) \mathrm{d} p+\int_{0}^{N} N_{\mathrm{c}}\left(\frac{p}{N_{\mathrm{c}}}\right)^{2 v}(N-p) \mathrm{d} p \\
& =N_{\mathrm{c}} a^{2}\left[\frac{2 v-1}{2(2 v+1)}\left(\frac{N}{N_{\mathrm{c}}}\right)^{-1}-\frac{2 v-1}{3(2 v+2)}\left(\frac{N}{N_{\mathrm{c}}}\right)^{-2}+\frac{1}{(2 v+1)(2 v+2)}\left(\frac{N}{N_{\mathrm{c}}}\right)^{2 v}\right] .
\end{aligned}
$$

$v_{\mathrm{G}}$ can then be calculated explicitely and is shown to increase monotonously from 0.5 to 0.6 . It reaches its asymptotic value at $N / N_{\mathrm{c}} \sim 10$ where the two first terms can be neglected with respect to the asymptotic behaviour

$$
R_{\mathrm{G}}^{2}=\frac{1}{(2 v+1)(2 v+2)} N_{\mathrm{c}}^{1-2 v} N^{2 v} a^{2} .
$$

Comparison with the $\theta$ solvent law

$$
R_{\mathrm{G}}^{2}=1 / 6 N a^{2}
$$

shows that for this model

$$
\frac{M}{M_{\mathrm{c}}}=\left[\frac{(2 v+1)(2 v+2)}{6}\right]^{\frac{1}{2 v-1}}
$$

\section{$\sim 2.2$ (see Fig. 3).}

We want to show that if one uses a more progressive cross over for $\left\langle r_{i j}^{2}\right\rangle$ it is possible to find apparent indices $v_{\mathrm{G}}$ higher than $v$.

A very simple way to introduce the cross over is to write $\left\langle r_{i j}^{2}\right\rangle$ in the form

$$
\left\langle r_{i j}^{2}\right\rangle=N_{\mathrm{c}}\left|\frac{i-j}{N_{\mathrm{c}}}\right|^{v_{\mathrm{h}}}
$$

where $v_{\mathrm{h}}$ is an effective exponent which varies from 0.5 at $N_{\mathrm{c}}$ to 0.6 at $N_{1}=k N_{\mathrm{c}}$.

When replacing (4) by (11) in the double summation, it is easy to see that, whatever the results of the integration between 0 and $N_{1}$ are for a given variation of $v_{\mathrm{h}}$ below $N_{1}$, the asymptotic behaviour of $R_{\mathrm{G}}$ is always the result of the same last integral as in (6) and will therefore be identical to (8) i.e. dependent on $N_{\mathrm{c}}$ only.

This result can easily be rationalized by saying that the asymptot is fully determined by the first deviation from the $\theta$ tricritical regime. What will differ however is the approach to the asymptotical behaviour. One can suspect that if $v_{\mathrm{h}}$ varies slowly from 0.5 to 0.6 in a rather broad interval $R_{G}$ will depart very slowly from its $\theta$ behaviour, so that the actual $R_{\mathrm{G}}$ versus $M$ variation will approach the asymptotic behaviour from below. This will necessarily require the effective index $v_{G}$ to take values higher than $v=0.60$.

This is fully confirmed by numerical calculation in which $v_{\mathrm{h}}$ has been given the two following variations :

a) $p>N_{\mathrm{c}}$

$$
v_{\mathrm{h}}=0.6-0.1 \exp \left|-c\left(\frac{p}{N_{\mathrm{c}}}-1\right)^{2}\right|
$$

b) $N_{\mathrm{c}} \leqslant p \leqslant k N_{\mathrm{c}}$

$$
v_{\mathrm{h}}=0.5+0.1\left(\frac{p-N_{\mathrm{c}}}{N_{\mathrm{c}}(k-1)}\right)
$$

$$
N \geqslant k N_{\mathrm{c}}
$$

$$
v_{\mathrm{h}}=0.6
$$

$c$ and $k$ being adjustable parameters which control the width of the cross over.

Results of the calculation are given in figure 1 for different values of $c, r$ and $k$, together with the result of relation (5). It is clear that the interpretation of experiments carried out in a range

$$
10 N_{\mathrm{c}}<N<100 N_{\mathrm{c}}
$$

in term of a power (scaling) law will lead to an apparent exponent higher than 0.60 . A mean value of 0.64 can be obtained in particular for the gaussian variation (12a) with $c=0.02$ as seen in figure 2. The effect is even more spectacular if one plot the expansion coefficient $\alpha_{G}=\left[\frac{R_{G}^{2}}{R_{G_{\theta}}^{2}}\right]^{1 / 2}$ as shown in figure 3 . It will be noticed that $M^{*}$ is now approximately $6 M_{\mathrm{c}}$.

Calculations using the same model have been carried out for the dynamic radius [7]

$$
R_{\mathrm{D}}=\frac{1}{2 N^{2}} \sum_{i} \sum_{j}\left\langle\frac{1}{r_{i j}}\right\rangle
$$




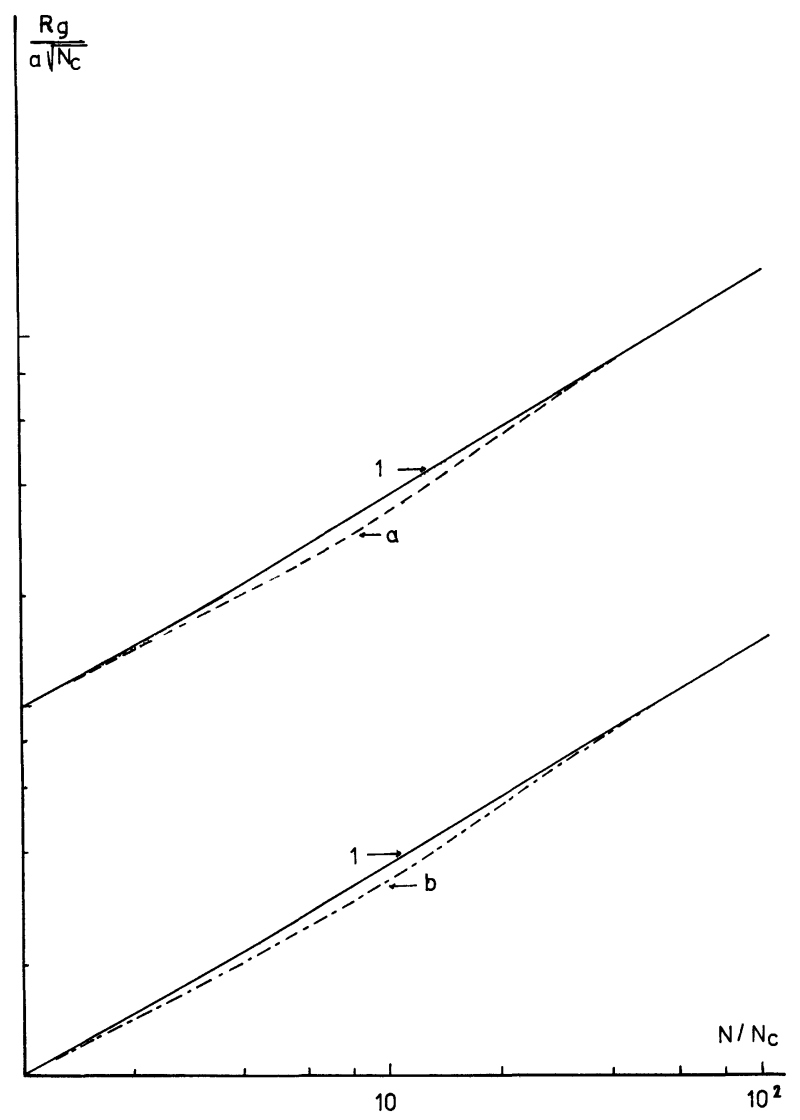

Fig. 1. - Dependence of the radius of gyration $R_{\mathrm{G}}$ with $N / N_{\mathrm{c}}$ in the cross over region : 1) statistics according to relation (4); 2) statistics according to relation (11) with, $a$ ) $v_{\mathrm{h}}$ according to (12a) with $c=0.02 ; b) v_{\mathrm{h}}$ according to $(12 b)$ with $k=15$.

and for the scattering factor :

$$
\frac{S(q)}{S(o)}=\frac{1}{N^{2}} \sum_{i} \sum_{j} \exp -\frac{q^{2}\left\langle r_{i j}^{2}\right\rangle}{6}
$$

The detailed discussion of the consistency of the model with the experimental results will be reported elsewhere [8]. It is important to notice that the observation of this cross over effect requires that the dimensions under study, either from the radius of gyration or from the whole scattering curve are of the order of magnitude of the radius of gyration of a chain of size $N_{\mathrm{c}}$. This was fortuitously the case for the polyacrylamide-water systems.

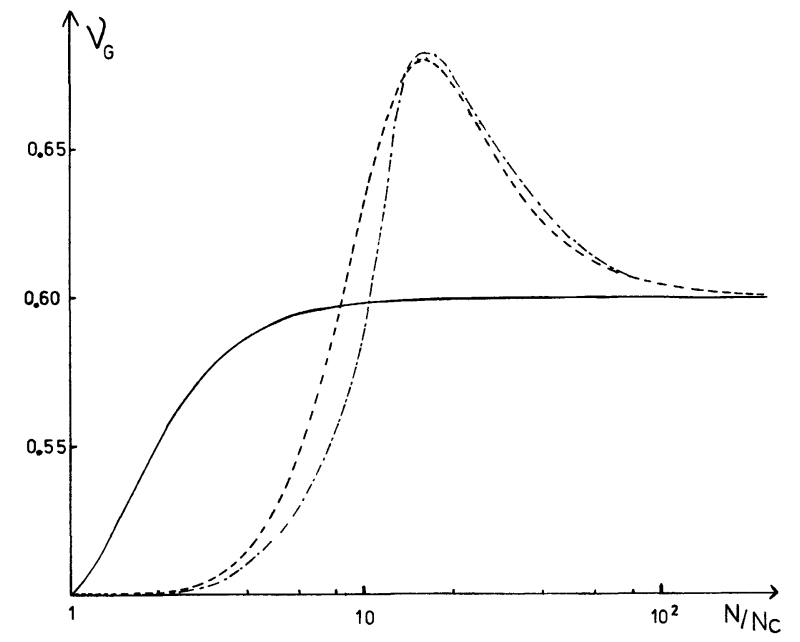

Fig. 2. - Variation of the effective index $v_{\mathrm{G}}$ with $N / N_{\mathrm{c}}$ : derived from model 1 of figure $1-$; derived from model $2 a$ of figure 1 -..-; derived from model $2 b$ of figure $1-\cdot-$

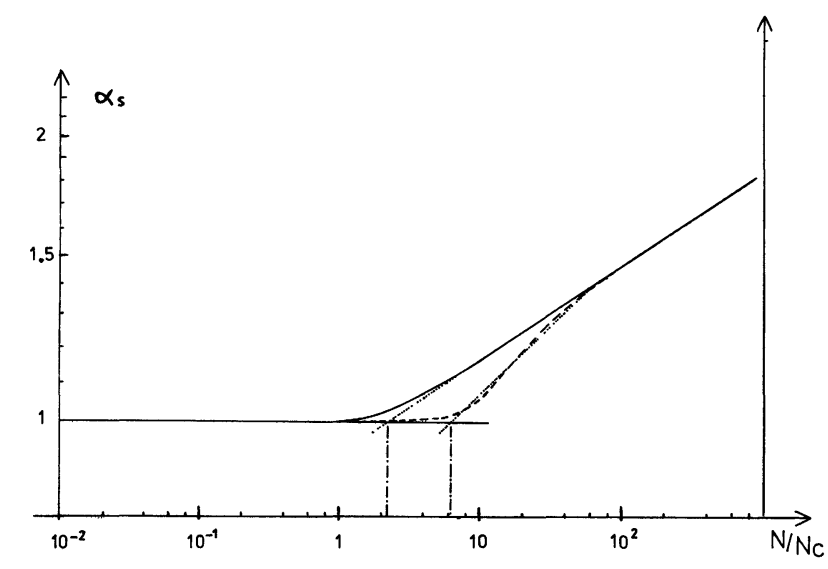

Fig. 3. - Variation of the expansion coefficient $d_{\mathrm{G}}$ with $N / N_{\mathrm{c}}$ derived from model 1 of figure 1 ; ---- derived from model $1 a$ of figure 1 .

A similar situation can be created either for light or neutron scattering with other polymer-solvent systems by a proper choice of the temperature above the $\theta$ point $\left(N_{\mathrm{c}} \sim \tau^{-2}\right)$.

There is therefore some hope to increase our experimental knowledge of the tricritical to critical cross over, as a basis for further theoretical justification of the width of the cross over.

\section{References}

[1] François, J., Sarazin, D., Schwartz, T., Weill, G., Polymer 20 (1979) 969.

[2] Loucheux, C., Weill, G., Benoit, H., J. Chim. Phys. 55 (1958) 540.

[3] Schwartz, T., François, J. and Weill, G., submitted to Polymer Communications.

[4] Sснмiтt, A., J. Physique Lett. 40 (1979) L-317.
[5] Schwartz, T., Sabadin, J., François, J., submitted to Polymer Communications.

[6] Farnoux, B., Boue, F., Cotton, J. P., Daoud, M., JanninK, J., Nierlich, M. and De GenNes, P. G., J. Physique 39 (1978) 77.

[7] Weill, G. and des Cloizeaux, J., J. Physique 40 (1979) 99.

[8] Schwartz, T., Thèse Strasbourg (1979). 